\title{
Severe Pulmonary Embolism Following Neglected Trauma of the Lower Limb : Management Difficulties in Resource-Limited Environment
}

\author{
SAÏ Servais Sontia ${ }^{1}$, ANGO Privat Désiré*, KONAN konan Dénis ${ }^{2}$, KONE Nabitou ${ }^{3}$ KOUAME \\ Kouadio Antoine ${ }^{1}$, BOUA Narcisse ${ }^{4}$ \\ *Anesthetist. Certifiicate of specialty study anesthesia reanimation, Clinic Manager's Assistant at Felix \\ Houpouet Boigny University in Abidjan; Abidjan Medical Sciences Training and Research Unit (UFR-SMA) \\ Republic of Côte d'Ivoire (RCI) \\ ${ }^{1}$ Internal Hospital, Hospital University (HU) of Treichville (RCI) \\ ${ }^{2}$ Certifiicate of specialty study anesthesia reanimation \\ ${ }^{3}$ Certifiicate of specialty study anesthesia reanimation, Anesthetist, Clinic Manager's Assistant; UFR -SMA \\ ${ }^{1}$ Internal Hospital; Hospital University (HU) of Treichville (RCI)
}

${ }^{4} \mathrm{Ph}$ D Certifiicate of specialty study anesthesia reanimation, University Professor, Alasane ouattara Unversity in Bouaké. Bouaké Medical Sciences Training and Research Unit (UFR -SM Bouaké) (Republic of Côted'Ivoire)

\begin{abstract}
*Corresponding Author: ANGO Privat Désiré, Anesthetist. Certifiicate of specialty study anesthesia reanimation, Clinic Manager's Assistant at Felix Houpouet Boigny University in Abidjan; Abidjan Medical Sciences Training and Research Unit (UFR-SMA), Republic of Côte d'Ivoire (RCI) Email: privatango@yahoo.fr
\end{abstract}

\begin{abstract}
Orthopedic injuries are known thrombogenic and are one of the major indications of thromboembolic prophylaxis. Therefore, the occurrence of pulmonary embolism $(P E)$ in orthopedic environment is not uncommon. We report a case of severe PE following closed trauma of the neglected femur in an environment with limited financial resources. Pulmonary CT angiography allowed the diagnosis to be made. In the absence of thrombolytics, orotracheal intubation, the mechanical ventilation and dobutamine were the therapeutic measures performed in emergency in view of the respiratory and circulatory distress. The clinical evolution of heparin therapy with Riva roxaban was favorable.
\end{abstract}

Keywords: Pulmonary embolism - neglected Trauma - Heparin therapy - Rivaroxaban

\section{INTRODUCTION}

Pulmonary embolism (PE) consists of the migration in the pulmonary arterial tree of a foreign body most often cruoric responsible for a brutal obliteration (total or partial) of the trunk or one of the branches of the pulmonary artery. It is called severe when it is associated with a state of shock [ 1,2$]$. Trauma and surgery of the lower limbs occupy a good place among the etiologies of this condition; hence the value of systematic thromboembolic prophylaxis.

In our tropics, orthopedic lesions are often neglected and thromboprophylaxis is sometimes omitted by practitioners. The risk of pulmonary embolism is therefore relatively increased in such a context; and the management remains difficult in the absence of the recommended means. The following illustration serves the purpose of describing the difficulties related to the prevention and management of severe pulmonary embolism resulting from neglected trauma in a context with limited resources.

\section{OBSERVATION}

Mrs. LH, 40, is admitted to intensive care for respiratory distress and sudden occurrence of consciousness disorder. The interrogation found a closed trauma of the right lower limb (photo 1) occurred 03 weeks earlier, for which the patient would have undertaken a self-medication based on analgesics and muscle massage. Faced with functional impotence and persistent pain after 2 weeks, she made a radiographic impact of the pelvis (following a consultation), which highlights a per trochanteric fracture of the right 
femur. She consults a physiotherapist (plasterer) who performs orthopedic treatment with pelvic pedicure (right hemi-bermuda). The patient is therefore followed on an outpatient basis with anti-inflammatory treatment and immobilization plastered without heparino prophylaxis. Five days later, she was admitted to the intensive care unit for dyspnoea complicating persistent pain in the lower right limb. The patient had no pathological history prior to the trauma.

The examination on admission noted a bad general impression, tachycardia at 115 beats per minute, blood pressure $86 / 42 \mathrm{mmHg}$, moderate pallor of the integument and temperature to 36.8 - C. The Body Mass Index (BMI) was evaluated at 31.22 (height $=165 \mathrm{~cm}$, weight $=85$ $\mathrm{kg}$ ). Pulmonary examination revealed acute respiratory distress with polypnea at 34 cycles per minute, signs of respiratory control, $88 \%$ of arterial saturation (in the air), and normal pulmonary auscultation. There was an obnubilation-type consciousness disorder with a Glasgow score of 13, with no sign of meningeal irritation or signs of localization. Upon removal of the right pelvic-pedicle plaster, there was swelling of the hip and right thigh with spontaneous and induced pain in the right hip when the limb was mobilized. The slugging of the calf and the sign of Homans could not be properly appreciated, considering the spontaneous pain and disturbance of vigilance. The examination of the abdomen was normal. The Wells score was estimated at 3 with a sPESI (Simplified Pulmonary Embolism Severity Index Score) score of 3.

An emergency biological assessment revealed leukocytosis at 22,260 elements $/ \mathrm{mm}^{3}$ with neutrophils predominating $(81 \%)$, normochromic normocytic anemia $(10.5 \mathrm{~g} / \mathrm{dl})$, venous hyperglycemia at $1.42 \mathrm{~g} / 1$ and d-dimer levels strongly elevated to $3894.61 \mathrm{ng} / \mathrm{ml}$. Blood gas analysis revealed hypoxemia $\left(\mathrm{PaO}_{2}=73 \mathrm{mmHg}\right)$ with hypocapnia $\left(\mathrm{PaCO}_{2}=32 \mathrm{mmHg}\right)$ associated with a decrease in $\mathrm{BE}(-4.4)$ and bicarbonate level (19.8mmol / 1). Hemostasis, ionogram and renal status were normal.

Radiographically, a thoracic CT scan performed 24 hours after admission revealed a right segmental lumbar pulmonary embolism (Photo 2). It was associated with bilateral alveolointerstitial pneumonitis and right pleurisy with contact atelectasis. The Doppler ultrasound of the lower limbs (D7 of the admission) had not objectified a deep or superficial vein thrombosis. A transthoracic echocardiography (TTE) could not be achieved.

Emergency management consisted of initial conditioning, orotracheal intubation and mechanical ventilation (taking into account respiratory distress). At the cardiovascular level, a vascular filling associated with Dobutamine was instituted. In the absence of thrombolytics, a treatment based on unfractionated heparin was instituted. Adjuvant therapy included multimodal analgesia and basic electrolyte fluid intake.

The evolution was marked by an improvement of the state of consciousness and the respiratory distress which allowed a weaning from the respirator by D2 of hospitalization. Unfractionated heparin was relayed with Rivaroxaban $30 \mathrm{mg}$ daily ( 2 doses of $15 \mathrm{mg}$ per os). After a 10-day stay in the intensive care unit, the patient was transferred to orthopedics for management of her pertrochanteric fracture.

\section{DISCUSSION}

The observation presented above reveals, not only a failure in preventing venous thromboembolism (VTED) in orthopedics, but also obstacles in the management of pulmonary embolism in Sub -Saharan Africa.

PE results from an interaction between permanent risk factors (patient-related) and temporary factors (environment-related). These risk factors are also classified according to their factor odd ratio strong", « moderate " or " low [ 1,3$]$. In our observation, three risk factors are found. These include obesity, lower limb injury, and prolonged bed rest, plus the absence of thromboembolic prophylaxis. The prolonged bed rest of our patient was due to the plaster immobilization performed wrongly in this type of lesion. Indeed, the treatment of a per trochanteric fracture remains resolutely surgical in the adult subject. This inadequate treatment reflects the fact that our patients often do not consult a specialist practitioner due either to a lack of financial resources, or of fear of surgery (cultural myth) or even illiteracy.

The omission of the prescription of a thromboembolic prophylaxis reaches a frequency of $15.3 \%$ in certain western series [2] and does not seem to be less frequent in our country, Côte d'Ivoire. This observation underlines the interest of raising the awareness of our medical and paramedical personnel about the interest of the systematic prescription 
of anticoagulant. In addition, the collegial management of such patients should be multidisciplinary (orthopedists - physio therapists - cardiologists).

The semiology of PE is variable and nonspecific [1,3]. Respiratory distress and tachycardi a are almost constant. The spiral chest angio-CT has been for more than two decades the Gold Standard for diagnosis. The radiological diagnostic algorithms for suspected pulmonary embolism are defined according to the existence or not of low blood pressure (state of shock). Thus a pulmonary embolism associated with a state of shock or a fall of the systolic blood pressure of more than $40 \mathrm{mmH}$ g within 15 minutes is considered as serious [1].

For some authors, dosages of D-dimer and arterial gasometry may not be useful in case of high clinical probability [3, 4-6]. Yet in the African tropics, most of our resuscitation units do not have ultrasound equipment at hand. In addition to this lack logistics, there is the lack of perfect collaboration between practitioners, which makes the mobility of radiology teams utopian. In such a context, the enhanced diagnostic scores of coupling D-dimer and arterial gasometry may prove to be essential tools for the diagnosis of PE of non-mobilizable patients and / or presenting hemodynamic instability.

In sub- Saharan Africa, the management of severe EP remains problematic because the patients, for lack of health insurance, find it difficult to meet the cost of their care, especially that of thrombolytics. These being rarely available in our hospitals. However, the medical means (vasopressor amines and anticoagulants) are most often available. For hemodynamic restoration, it is recommended to limit the volume expansion to $500 \mathrm{ml}$ and use (in case of persistent shock) dobutamine in first intention $[5,6]$, then thrombolysis relayed by heparin therapy [1]. In our case, the latter was relayed by Rivaroxaban as soon as the oral route was possible.

Finally, it should be noted that pulmonary embolism following a plastered immobilization of the lower limb, will subsequently cause problems during the surgical treatment of the fracture. These problems, mainly due to the perioperative management of anticoagulants, represent a challenge for the anesthesiologist.

\section{CONCLUSION}

This observation highlights the importance of prevention of thromboembolic disease in femur trauma. The management of VTED must first be accentuated on prophylactic measures.

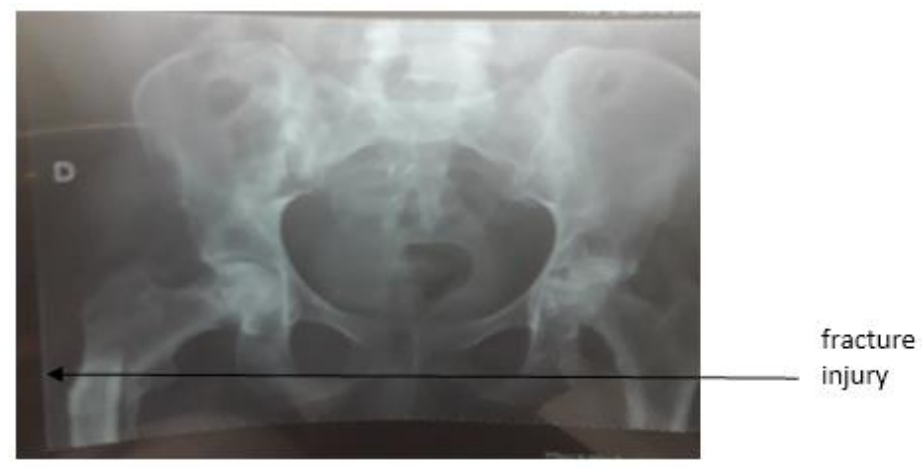

Photo1. Closed fracture of the right femur

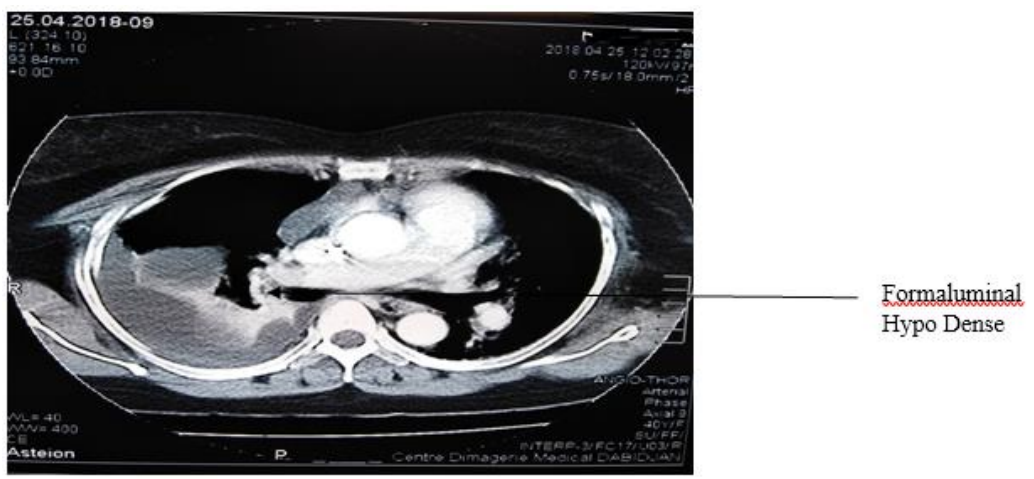

Photo2. Right lobar and segmental pulmonary embolism associated with moderate pleurisy with contact atelectasis 


\section{AUTHOR CONTRIBUTIONS}

All authors read and approved the final version of the manuscript.

\section{ACKNOWLEDGEMENTS}

We would like in the framework of the realisation of this work to thank all our collaborators (cardiologist, Hematologist) from the University Hospital (CHU) of Treichville, wo too an active part in the management of our study population

\section{REFERENCES}

[1] Konstantinides SV, Torbicki A, Agnelli G, Danchin N, and al. 2014 ESC Guidelines on the diagnosis and management of acute pulmonary embolism. Eur Heart J. 2014 ; 35 (43): 303369

[2] Gudipati S, Fragkakis EM, Ciriello V Harrison SJ, and al . A cohort study on the incidence and outcome of pulmonary embolism in trauma and orthopedic patients. BMC Med. 2014 ; 12:39. https://doi.org/10.1186/ 1741-7015-12-39
[3] Galanaud J-P, Blanchet-Deverly A, Pernod G, Quéré I. Prise en charge de l'embolie pulmonaire en 2015. J Mal Vasc. 2016 ; 41: 5162

[4] Meneveau N. Nouvelles recommandations de l'ESC sur l'embolie pulmonaire : le traitement anticoagulant et thrombolytique. Arch Mal Coeur Vaiss Prat 2015;2015 (241):8-15

[5] Planquette B, Belmont L, Meyer Guy, Sanchez O. Prise en charge diagnostique et thérapeutique de l'embolie pulmonaire grave. Rev Mal Respir. 2011; 28(6):778-89. doi: 10.1016/j.rmr.2010.11.006.

[6] Roy, P.-M., Bordot, A.-S., Bichri, A., Sivova, N., Delvau, N., \& Pattier, K.. Prise en charge de l'embolie pulmonaire en urgence. Pratan, 2008: 12(6), 440-447. doi:10.1016/j.pratan. 2008.10.006

Citation: SAÏ Servais Sontia, ANGO Privat Désiré, KONAN konan Dénis, KONE Nabitou, KOUAME Kouadio Antoine, BOUA Narcisse, Severe Pulmonary Embolism Following Neglected Trauma of the Lower Limb : Management Difficulties in Resource-Limited Environment. ARC Journal of Clinical Case Reports. 2019; 5(2): 7-10. doi:dx.doi.org/ 10.20431/2455-9806.0502003.

Copyright: (c) 2019 Authors. This is an open-access article distributed under the terms of the Creative Commons Attribution License, which permits unrestricted use, distribution, and reproduction in any medium, provided the original author and source are credited. 